\title{
THE ROLE OF SPECIFIC TECHNOLOGICAL SOLUTIONS IN THE CREATION OF WELLNESS PROGRAMMES
}

\author{
Ivan Živković \\ Singidunum University, \\ Belgrade, Serbia
}

Correspondence:

Ivan Živković

e-mail:

ivan_zivkovic@outlook.com

\begin{abstract}
:
Changing of bad habits and the desire for a healthy lifestyle direct people into wellness centres which are providing programmes focused on individuals, which lead to optimized physical and mental condition. Using only precise information obtained by measuring and through assessment of the complete body status and through detailed analysis, can provide the creation of relevant wellness programmes and necessary treatments in the process of eliminating misbalance and improving the overall conditions. InBody 770 used to measure body composition and the different ratios between tissues, is proven to be a highly accurate device compared to a reference device, and as such, it is necessary in the creation of specific programmes and assessment of the effects of selected activities. Analysis of possibilities of the already proven Templo software has demonstrated its abilities in the assessment of postural status, analysis of foot structure, as well as in the functional analysis of movement. Portable devices for monitoring users' daily activities proved to be precise, compared to the reference model. Use of technological solutions proved to be unavoidable when it comes to reaching the optimal goals and positive change of the overall condition and habits of users, in combination with correctly created wellness programmes.
\end{abstract}

\section{Keywords:}

wellness and health, recreation, InBody, Smartwatch.

\section{INTRODUCTION}

Due to the modern lifestyle, people are often orientated towards taking care of their physical and mental health. Wellness centres provide a way of achieving adequate conditions by designing specially created services such as weight-loss programmes, personal fitness training, group exercise classes, spa services, massage therapy, physical therapy, corrective body treatments, wellness education classes [1].

Wellness and recreational centres, as well as all the facilities oriented towards the promotion of healthy lifestyle by applying specific procedures and activities, in order to provide adequate wellness contents, need to adjust activities to their users, based on their physical condition, desires and needs [1]. 
Only through correctly and precisely designed programmes and activities the user will feel the benefits of wellness programmes [2]. A satisfied user will bring benefit to the service provider, and thus to popularisation of wellness as a lifestyle that has a positive impact on the quality of life itself. Efficient programmes, focused on individuals, result in an increase in the wellness industry in general, including the development and popularisation of wellness-based tourism, which has strong predispositions to be among the most sought after tourist attractions in the Republic of Serbia [3].

The wellness programmes must be applicable and useful for the user, which is achieved by offering properly prepared client-centered solutions. These solutions must enable progress for the user in the most efficient, safe and the fastest way, in line with their expectations and beyond this, so that by using those solutions, the user feels positive changes and commitment to the centre where they exercise. This is achieved by collecting, analysing and interpreting the necessary and adequate information about the user, including a physical health check of the user, bearing in mind that they can be recreational, amateur and professional athletes, convalescents, older persons, children, and overall, all those who want to improve their quality of life and adopt healthy habits that can help them [4]. If there is knowledge about the current status of the body, and all the found deficiencies, individual programmes that help eliminate those problems can be created, prevention can be exercised, and the result will be the improvement of psychosomatic and functional status. Different problems and deficiencies can occur due to poor lifestyle, inadequate nutrition, weak or insufficient physical activities, as well as inherited or developed deformities, injuries, or other factors [2].

Technological progress and finding of different technological solutions, as well as development and optimization of the existing technologies, provide for optimal collection and analysis of the information and monitoring of all the processes aimed at achieving the desired goal. This paper will show and describe the validity of different technological solutions applied in diagnostic examination in wellness, sport and recreation, enabling as precise information as possible, based on which, through analysis and interpretation, relevant wellness and sports and recreational programmes can be created.

\section{TECHNOLOGICAL SOLUTIONS IN THE WELLNESS INDUSTRY IN THE DIAGNOSTICS AREA}

\author{
Bioelectrical impedance InBody 770
}

The evaluation and analysis of the body composition and different relations between tissues are necessary in order to properly design different wellness programmes and treatments which will bring the client to optimal condition [5]. The modern technological solution InBody 770 offers high precision in measurement, providing necessary information to determine the client's psychosomatic status [6]. It enables a detailed analysis of the data used by experts in the field of recreation, sports, medicine, therapy to be certain when prescribing the best solutions, which include nutrition, hydration, training and therapy processes for the achievement of the optimal overall condition of the client.

The device is based on the reactivity analysis method, it uses six different frequencies through five different body segments, discerning each and their mutual relation, providing relevant data about more than 50 parameters regarding body composition [6]. Qualitative and quantitative data about electrical conductivity of tissue enable assessments for full-body, its segments, the amount and distribution of body fat, muscles, proteins, minerals, the total water levels, as well as the ratio between fluids in and outside of the cells, which enables assessment of the possible presence of edema in certain segments of the body [7].

The information gained through measurement is subject to further analysis in order to prepare adequate nutrition, training programmes and other therapy procedures which can help the client get into the desired condition.

A number of research studies have confirmed high accuracy of InBody device by comparing it with a reference device, the DXA - Dual-energy X-ray absorptiometry (bone density scanning) [8], [9], [10]. DXA is considered a standard in the measurement of body composition and its usage is confirmed in many clinical trials [11], [12]. The device enables measurement of the entire bone mass, percentage of bone and muscle mass, where the percentage of the body fat is specified, providing precise data which are used in the preparation of different obesity treatments, to follow up on losing of body mass with recreational and professional athletes. 
Bioelectrical impedance analysis - BIA is widely used because it is non-invasive, easier to use, faster, cheaper and its efficiency is established by many studies which confirm its high accuracy [13]. Wen-Hui Fang et al. conducted a research [8] on the population of the elderly persons in Taiwan, where they tested the accuracy of the displayed body composition parameters of test subjects by applying the BIA InBody 720. DXA has been used as a reference device and BIA as a model which has been considered accurate enough when it comes to measurement of the body composition of the elderly. The research has shown that information provided by BIA InBody 720 have a high correlation with the information provided by the DXA device. The correlation coefficient of those two devices for the muscle mass was 0.969 and for fat tissue 0.935. Comparison of the BIA and DXA methods has been a part of the research conducted by Antonio Jose et al. [9], which provides a comparative analysis of the data received by using methods of different technologies (DXA and BIA InBody 770) in four weeks' treatment of the men and women in training. The examinees have been advised to conduct an identical workout programme and reduce energy input by using specific nutrition, in order to measure the value of changes in body composition. They have been measured before and after the programme and it was established that the percentage of weighted fat component, the percentage of fat tissue, has dropped, and at the same time the muscle component was above values measured by DXA method. The changes in percentages of the fat component, before and after the measurement done by DXA compared to those done by BIA, was $-1.1 \%$ and $-1.5 \%$, respectively. The results of the mentioned components did not show statistically significant differences vis-a-vie DXA method and, although is they showed higher variability level, they have confirmed the high accuracy of the BIA method applying the InBody 770 apparatus, and it was concluded that BIA is a solid replacement for the DXA method when it comes to measurement of the body composition of males and females regularly performing physical activities. Similar results have been reached by Schoenfeld et al. [10], who have compared DXA and BIA by merasuring younger male examinees after ten days of resistance training process. It has been shown that there is no significant statistical difference between these two methods (fat tissue percentage in DXA - 1.05\%, $1.28 \%$ in BIA method).

By analysing the collected data, the experts are gaining precise data based on which they can create specified programmes which contribute to the positive changes in clients by providing the best ways to solve certain issues [14].
Wellness programmes created this way are becoming more severe and they contribute to the trust of clients in the wellness centre. For example, my measurement experts determine obesity levels of the client and by performing detailed tests, they get an overview of the complete body condition and decide where it is necessary to give relevant advice and a specified program of activities, nutrition and recovery. Many individuals attempt starvation, where the elimination of sugar and processed food from one's diet can have short term result. Instant weight loss with inadequate activities is not good, because very soon all the weight will come back, even more than before [15], [5]. For a stable process of weight loss, stable burning of calories is only provided through adequately prepared, dosed physical activity combined with adjusted nutrition, the establishment of healthy habits and introduction of proper methods of recovery from stressful daily activities, by respecting the current body status and genetic predispositions [16].

Wellness centres can be in non-stop contact with their clients by using Cloud database about clients with advanced analytics, as well as InBody mobile application via which the clients can see the results and follow the progress, and that helps them stay motivated and focused on achieving their desired fitness [17]. Connection with friends and family is also enabled, as well as the link with their personal trainer so that they can exchange information and have an overview of the condition.

\section{Contemplas Templo professional motion analysis software}

For assessment of the postural status, Templo software is using a system of three cameras which detect markers on certain anthropometrics body points in all three planes. The developed 3D analysis provides precise information about postural disorders and curves of the spine. With a platform that detects pressure distribution under the foot during standing and walking, eventual deformities of the feet can be noticed [18]. Figure 1 shows the 3D analysis of posture done by Templo software. 


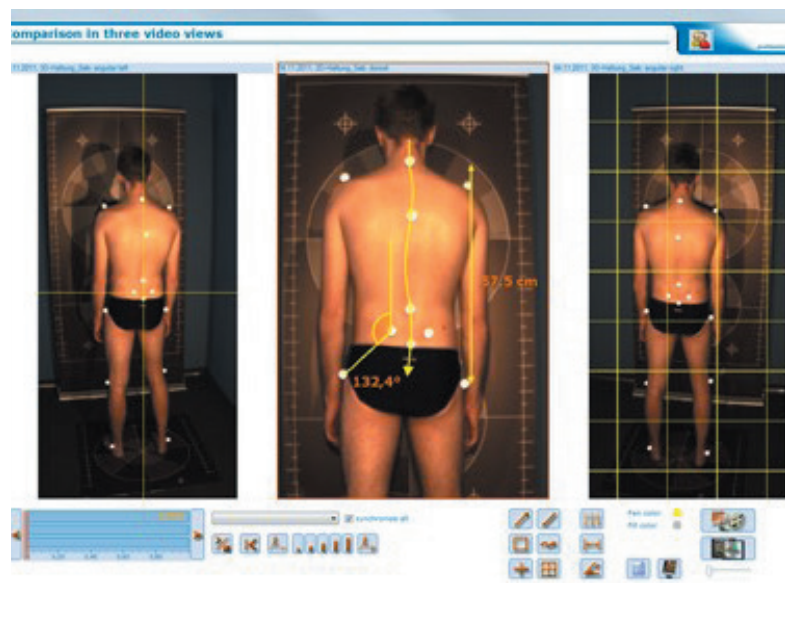

Figure 1.3D posture analysis [19].

The importance of the collection of this specific data is demonstrated with precise diagnostics of the current condition of the client and adequate determination of the kinesiotherapy treatment, as well as the providing of correct advice during the performance of different physical activities, so that they don't have a negative effect on the body or create bigger issues. In order for activities to be efficient and effective, it is necessary to perform them in accordance with biomechanical principles [20]. Templo software allows diagnostics by the FMS (Functional Movement Screen) method, which has significant usage in functional assessment of locomotor apparatus and it determines the stability and mobility of certain body parts [21]. It has extensive usage in team sports as well as in recreation, wellness and kinesiotherapy. The system consists of a computer, a flashlight and two cameras - frontal and back, a special platform and a measuring terminal that simplifies its operation. The method allows for evaluation of the correctness of movement during the performance of seven tests, which are used to determine limitations of stability and mobility of the client's movements, as well as to determine asymmetry [22].

Analyses of movement and running are very complex [20] and, thanks to these technological solutions it is possible to collect precise data for analysis of the condition of a large number of clients. Templo software is designed as a modular platform which can be upgraded with different functions, depending on the preferable analysis of posture or movement which are necessary for the preparation of the required programmes, as well as, depending on the wellness centre, in rehabilitation or other medical facilities, sports and recreational centres, sport clubs. Sport University Cologne [18] has confirmed the preciseness and importance of the Contemplas
Templo technology and found its applicability in both commercial and scientific field.

\section{Portable device for daily activities monitoring}

With the promotion of a healthy lifestyle, the popularity of portable devices for the monitoring of an individual's daily activities is increasing, and that is also confirmed by major tech companies like Samsung, Apple, Garmin, Fitbit - theyare producing multifunctional solutions and permanently developing them. For an individual to have a healthy lifestyle, the World Health Organization recommends physical activity at least 60 to 150 minutes per week for adults between 17 and 64 years of age [23]. So-called smartwatches and Fitness trackers (fitness bracelets) have become popular because it's possible to use them paired with smartphones via matching applications, and the tracking of different daily activities provides detailed information about every activity of the user during one day. Apart from different functions that they offer, the most common and most popular features of different smartwatches are the heart rate measurement, step counter, calorie burn, sleep tracker, running tracker, stairs counter [24]. All the information can be seen and analysed with matching apps on a smartphone or computer. That kind of monitoring is enabled thanks to different sensors, such as [25]:

- Accelerometer - the most important sensor which can detect wide spectre of activities: detect movement or inaction of the device, inclination, shaking, step counter.

- Gyroscope - for the navigation and angular velocity measurement

- Geomagnetic sensor - used as the compass in devices, it measures the surrounding magnetic field in all three physical axes.

- Barometer - based on measured atmosphere pressure, velocity and mode of movement, it can calculate calories burn

- Heart rate sensor - heart rate monitoring, used for information about the intensity of the activity, lassitude, and quality of sleep.

The reliability and preciseness of portable devices in the collecting of valid information about user activities are confirmed in various studies [26], [27]. Those studies had to compare it with the device Actigraph GT3X, which has the status of a reference device when it comes to the accuracy 
of the data on user activities within clinical studies [28]. The conclusion was that devices such as Apple smartwatch and Fitbit are precise enough for the monitoring of daily physical activities of the user, but they cannot be an adequate replacement for clinical usage and research.

Use of daily activities monitoring devices provides information significant for the experts in wellness centres, kinesiology and medical facilities, sports clubs so that they can be in constant communication with the clients with the help of apps [29], [30]. In that way, they can analyse the information adequately and timely and use this to prepare relevant wellness programmes and other activities and treatments that follow the daily regime of the client and their business and private commitments, trips, hobbies, to achieve the best possible results.

The users who want to practise different physical activities need to conduct consultations with the experts from the fields of sport, recreation, kinesiotherapy, medicine and conduct a detailed diagnostic examination in the wellness centre and medical facilities. These facilities have the most modern and precise methods for determining the overall physical condition, based on which the clients can receive individually adjusted programmes which can bring them into the desired condition. Smartwatches and similar devices can be useful for monitoring purposes, as a motivation to fulfil the goals, in communication with the wellness service providers, as well as in the analysis of daily activities of the clients. That way, they can track progress, as well as the influence of selected activities to changes in the condition of the body [31]. In a population with obesity problems or cardiological issues, usage of smartwatches can be a default addition to the physical activities due to the timely sent signals about heart rate and control of activities in order to avoid side-effects such as sudden loss of energy and premature fatigue, nausea, muscle cramps, etc. [16]. The constant development of wellness tourism, which bases part of its offer on outdoor activities, smartwatches facilitate communication with users and wellness centres, as well as the implementation of planned field programmes and constant monitoring of different activities conducted in different conditions, providing the opportunity to receive timely and correct information necessary for control of the prescribed programmes.

It is mandatory to confirm the validity of this type of devices through different studies, along with the possibilities for development of a system which can enable them to reach the standard to be used for clinical purposes. With relevant studies, it is possible to differentiate devices that justify its purpose and those that are less functional and less precise, and with this the user can be protected from the manipulation and will be safe to improve his physical condition to the desired level.

\section{CONCLUSION}

A healthy lifestyle and achieving optimal body condition is a result of efforts to change one's bad habits and of orientation towards the performance of different activities which enable that change and the reaching of the designated goal. Wellness centres, kinesiology and sports and recreational centres, specific medical facilities can provide the most optimal approach to this problem and its elimination by applying individually designed wellness programmes based on relevant information. In order to provide that, it is necessary to have the correct diagnostics of the overall body condition of the client using precise measuring devices to collect information for analysis and to prepare the proper programmes. The advancement of technology allows the development of precise devices which can receive necessary information about the body and functional deficiencies in a non-invasive way, so that they can be removed in the fastest and most optimal manner, but they can also improve the overall condition to make permanent changes.

The use of InBody device, of bioelectrical impedance, has proven to be an unavoidable method in the measurement and analysis of body composition of the client, enabling insight in the overall body structure and a very precise display of percentages of different types of tissue. This enables the preparation of a diet and recommendations for the planning of the needed practises and other wellness activities.

To avoid side effects of exercises, it is necessary to move by following biomechanical principles and to assure efficient and correct performance of movement to make the right changes which will not leave consequences on bones and joints or the muscular system. Only by performing a precise determination of the postural status, foot structure, analysis of movement and establishing all types of present disbalances, it is possible to design optimal and individually focused wellness and kinesiology programmes and other needed treatments and activities.

Contemplas Templo has proven itself as a very accurate and scientifically confirmed solution, as a professional software for the analysis of motion which, as a modular platform, can be upgraded with different functions, depending on the current needs. 
The desire for a healthy lifestyle has been recognised by major technology companies as an opportunity to offer to the market devices which can monitor daily activities of the user, by using their technology such as smartwatches and fitness trackers. These multifunctional devices are designed to measure different activities of the user, like distance, heart rate, calories deficit, sleep quality and similar. Use of specially designed apps on mobile phones and computers and implemented tools for daily activities analysis and communication, provides the user, as well as the wellness centres, with the necessary insight into the current status, results and progress in achieving the desired goals. One should keep in mind that those devices are made exclusively for monitoring of activities so that they can influence the motivation of the users and fulfilment of the set goals and their communication with friend, family and wellness centres. Various studies have confirmed the reliability of some of the devices, but they cannot be substituted for clinical usage in research. It is also mandatory, through further research and development, to strive for that kind of possibilities.

We can conclude that it is necessary to use modern technological solutions which are intentionally designed to enable the recording of the overall status of clients as well as the monitoring of activities in the implementation of the prescribed programmes and treatment in achieving the desired goals. This way, the user is permanently informed and timely advised by the selected facilities that offer wellness programmes and specified treatments for eliminating deficiencies and introducing a positive change in the lifestyle. Although the conducting of tests within facilities is often more appreciated, it is not recommended to carry out the programmes on your own without consultations with professionals, because the relevance of the data and expert advice enable the safest and most secure way of eliminating deficiencies and achieving the desired results, along with the minimising of side effects.

\section{REFERENCES}

[1] S. J. Hoffman, D. V. Knudson. Introduction of kinesiology: Studying physical activity. 5th Edition. USA: Human Kinetics. 2018.

[2] D. Mitić. Značaj fizičke aktivnosti u prevenciji i terapiji gojaznosti u detinjstvu i adolescenciji. Medicinski glasnik Specijalne bolnice za bolesti štitaste žlezde i bolesti metabolizma 'Zlatibor'. 2011, 16(39):107-112.
[3] Strategija razvoja turizma Republike Srbije za period 2016-2025., 2016, dostupno na https://mtt.gov.rs/ download/3/strategija.pdf dana 18. 2. 2020.

[4] C. E. Garber, B. Blissmer, M. R. Deschenes, B. A Franklin, M. J. Lamonte, I. M. Lee, D. C. Nieman, D. P. Swain. Quantity and quality of exercise for developing and maintaining cardiorespiratory, musculoskeletal, and neuromotor fitness in apparently healthy adults: guidance for prescribing exercise. American College of Sports Medicine position stand. 2011, 43(7): 1334-1359.

[5] S. Stojiljković, D. Mitić, S. Mandarić, D. Nešić (2005). Fitness. Beograd: Fakultet sporta i fizičkog vaspitanja. 2005.

[6] InBody Technology. https://inbodyusa.com/general/technology/, Accessed 19 February 2020.

[7] InBody Body Composition Analysers, http:// inbody.net.au/wp-content/uploads/2018/09/InBody_770_Information_pack_04.pdf, Accessed 19 February 2020.

[8] W. H. Fang, J. R. Yang, C. Y. Lin, P. J. Hsiao, M. Y. Tu, C. F. Chen, D. J. Tsai, W. Su, G. S. Huang, Chang H, S. L. Su. Accuracy augmentation of body composition measurement by bioelectrical impedance analyzer in elderly population. Medicine 2020; 99:7(e19103).

[9] J. Antonio, et al. Comparison of Dual-Energy X-ray Absorptiometry (DXA) Versus a Multi-Frequency Bioelectrical Impedance (InBody 770) Device for Body Composition Assessment after a 4-Week Hypoenergetic Diet. Journal of Functional Morphology and Kinesiology. 2019, 4(2), 23.

[10] B. J. Schoenfeld, et al. Comparison of Multifrequency Bioelectrical Impedance vs. Dual-Energy X-ray Absorptiometry for Assessing Body Composition Changes After Participation in a 10-Week Resistance Training Program. Journal of Strength and Condonditioning Research. 2020; 34(3): 678-688

[11] C. Verdich C., et al. Changes in body composition during weight loss in obese subjects in the NUGENOB study: Comparison of bioelectrical impedance vs. dual-energy X-ray absorptiometry. Diabetes \& Metabolism. 2011; 37 (2011) 222-229.

[12] K. H. Pietila, S. Kaye, A. Karmi, L. Suojanen, A. Rissanen, K. A. Virtanen. Agreement of bioelectrical impedance with dual-energy X-ray absorptiometry and MRI to estimate changes in body fat, skeletal muscle and visceral fat during a 12-month weight loss intervention. British Journal of Nutrition, 2013, 109 (10): 1910-1916.

[13] P. L. Cox-Reijven, B. Van Kreel, P. B. Soeters. Accuracy of Bioelectrical Impedance Spectroscopy in Measuring Changes in Body Composition During Severe Weight Loss, Journal of Parenteral and Enteral Nutrition. 2002, 26(2): 120-127. 
[14] D. Riebe, J. Ehrman, G. Liguori, M. Magal, (Eds.). ACSM's guidelines for exercise testing and prescription. Tenth edition. USA: LWW. 2017.

[15] B. Bushman, (Ed.). ACSM's complete guide to fitness \& health. Second edition. USA: Human Kinetics. 2017.

[16] N. Dikić, S. Živanić. Osnove monitoringa srčane frekvencije u sportu i rekreaciji. Beograd: Dikić Nenad-Živanić Slobodan. 2003.

[17] InBody kraj teksta aplikacija (InBody App. https:// inbody.net.au/inbody-app/, Accessed 19 February 2020.

[18] D. Madić. et al. Improving testing abilities on postural and spinal column status. Novi Sad: Alfa-Graf NS, 2014.

[19] TEMPLO 3D posture analysis protocols. Dostupno na https://www.contemplas.com/posture_ analysis_3d_schemes.aspx , dana 23.2.2020.

[20] P. Grimshaw, N. Fowler, A. Lees, A. Burden. BIOS Instant Notes in Sport and Exercise Biomechanics. USA: Taylir \& Francis Group. 2006.

[21] C. Agresta , M. Slobodinsky, C. Tucker. Functional Movement Screen TM - Normative Values in Healthy Distance Runners. International Journal of Sports Medicine. 2014, 35(14): 1203-1207.

[22] Templo Functional Screening. Dostupno na https:// www.contemplas.com/motion_analysis_functional_screening.aspx , dana 23.2.2020.

[23] Physical activity. Dostupno na https://www.who.int/ news-room/fact-sheets/detail/physical-activity, dana 24. 2.2020 .
[24] N.Aitken. Most Used Features of Smartwatches. https://whatphone.com.au/guide/most-used-featuresof-smartwatches, Accessed 21 March 2020.

[25] B. Reeder, A. David. Health at Hand: A Systematic Review of Smart Watch Uses for Health and Wellness. Journal of Biomedical Informatics. 2016. 63: 269-276.

[26] M. Breteler, J. Janssen, W. Spiering, C. J. Kalkman, MD, W. W. van Solinge, D. AJ Dohmen. Measuring Free-Living Physical Activity With Three Commercially Available Activity Monitors for Telemonitoring Purposes: Validation Study. JMIR Form Res. 2019 Apr-Jun; 3(2): e11489.

[27] P. Semanik, J. Lee, C. A. Pellegrini, J. Song, D. D. Dunlop, R. W. Chang. Comparison of Physical Activity Measures Derived From the Fitbit Flex and the ActiGraph GT3X+ in an Employee Population With Chronic Knee Symptoms. ACR Open Rheumatology. 2020. 2(1): 48-52.

[28] J. E. Sasaki, Dinesh John, P.S. Freedson. Validation and comparison of ActiGraph activity monitors. Journal of Science and Medicine in Sport. 14 (2011) 411-416.

[29] Fitbit App. https://www.fitbit.com/eu/app , Accessed 21. February 2020.

[30] Health App. https://www.apple.com/ios/health/, Accessed 21. February 2020.

[31] C. Dobbins, R. Rawassizadeh, E. Momeni. Detecting physical activity within lifelogs towards preventing obesity and aiding ambient assisted living. Neurocomputing. 230 (2017): 110-132. 